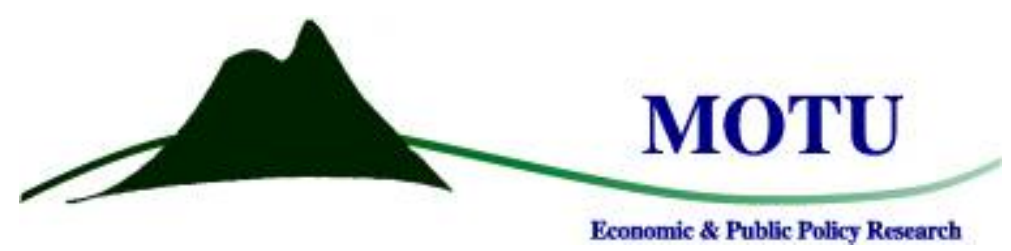

\title{
DO LOWER EXPECTED WAGE BENEFITS EXPLAIN ETHNIC GAPS IN JOB-RELATED TRAINING? EVIDENCE FROM NEW ZEALAND
}

\author{
John Gibson University of Waikato and Motu Affiliate \\ Motu Working Paper \# 2003-03 ${ }^{1}$
}

\begin{abstract}
March 2003
John Gibson (jkgibson@waikato.ac.nz) is a Senior Lecturer at the University of Waikato and a member of the Motu Affiliate Programme. The financial support of the Department of Labour, the Ministry of Education, the New Zealand Treasury and the University of Waikato is gratefully acknowledged. Access to the data used in this study was provided by Statistics New Zealand in a secure environment designed to give effect to the confidentiality provisions of the Statistics Act 1975. The results in this study and any errors contained therein are those of the author, not Statistics New Zealand.
\end{abstract}

\footnotetext{
${ }^{1}$ (c) 2003 Motu Economic and Public Policy Research Trust. All rights reserved. No portion of this paper may be reproduced without permission of the authors. Motu working papers are research materials circulated by their authors for purposes of information and discussion. They have not necessarily undergone formal peer review or editorial treatment. ISSN 1176-2667.
} 


\section{ABSTRACT}

Many studies show that individuals from ethnic minority groups receive low levels of job-related training, raising the question of whether lower expected wage benefits contribute to this lack of training. In this paper, unit record data are used to examine the effect of job-related training on wages in New Zealand. The results suggest that both the receipt of employer-provided training, and the number of training events, have larger effects on wages for minority workers than they do for white workers. There are no differences across ethnic groups in the wage benefits from other types of training.

JEL: J15, J31

Keywords: Earnings; Job training; Minorities; Selectivity 
A common finding in studies of job-related training is that individuals from nonwhite ethnic minority groups have a lower likelihood of being trained. ${ }^{2}$ Because training may improve earnings, occupational status and job security Blundell et al., (1999) this lack of training could contribute to permanent labour market disadvantages for these ethnic groups. However, less is known about the causes of these ethnic gaps in the incidence of training. For example, Shields and Wheatley Price (1999) suggest that gaps may arise because of the poorer response by non-whites to training opportunities, because of employers' beliefs about the low returns from training non-white employees or because of some discrimination on the part of employers.

One possible cause of poor response to training opportunities by ethnic minorities might be that they expect smaller wage benefits. Because wages should reflect productivity, smaller wage benefits might also indicate lower returns to employers, making it less likely that non-whites receive training offers. ${ }^{3}$ But few of the econometric studies of training and wages follow the lead of Flanagan (1974) in estimating separate wage equations to allow training effects to vary between whites and non-whites. ${ }^{4}$ This is surprising because some of these studies find unexpectedly higher wage benefits of training for non-whites, making it harder to understand why minority workers have a lower likelihood of being trained. For example, Flanagan (1974) finds that the mean level of training for young black workers is less than one-half that of white workers, but training raises the wages of black workers by 13 percent compared to only 7 percent for white workers. Lynch (1992) reports similar evidence of relatively high wage benefits from comparatively low levels of training for non-whites.

\footnotetext{
${ }^{2}$ Examples from the U.S. include Duncan and Hoffman (1979), Blakemore and Low (1983), and Lynch (1992), while from the U.K. they include Greenhalgh and Stewart (1987), Arulampalam and Booth (1997), and Shields and Wheatley Price (1999). In Australia, immigrant workers from a non-English-speaking background have significantly lower probabilities of receiving training (VandenHeuvel and Wooden, 1997). Studies that find no evidence of ethnic differences in the incidence of training include Booth (1991), Veum (1995), and Veum (1996). The only studies to find significantly higher training probabilities for non-whites are Altonji and Spletzer (1991) and Booth (1993).

${ }^{3}$ In this paper benefits are distinguished from returns. Returns require some consideration of the cost of training, whereas benefits do not. In the empirical section, attention is restricted to the wage benefits of training because no information is available on costs.

${ }^{4}$ This approach is limited to Duncan and Hoffman (1979), Blakemore and Low (1983), Lynch (1992) and Sexton and Olsen (1994).
} 
Other studies also show that workers with low social and economic status have high returns from training but low participation in it, although there is debate about the policy implications of this pattern Blundell et al (1999). One view is that there is socially-inefficient rationing of training, so policies driven by equity considerations - such as extending training to groups with low participation rates - might also be efficient because of the high wage returns for these groups OECD (1999). This is in contrast to the comparative advantage view, where endogenous selection means that those who do not receive training are those for whom the returns are lowest Groot et al (1994), so that extending training to new groups may come at the cost of efficiency. Under the comparative advantage view, the reported high wage benefits may just reflect the high costs of training disadvantaged groups (given that training would not be observed if benefits did not exceed costs).

In light of these debates, this paper re-examines the question of whether non-white workers have greater wage gains from job-related training than do white workers. Confidential unit record data from the New Zealand Education and Training Survey (ETS) are used to estimate separate wage equations for ethnic groups. New Zealand is a setting where ethnic minorities have significantly poorer labour market outcomes Te Puni Kokiri (1998), which are mirrored in their lower participation in job-related training Gobbi (1998). In response to these disparities, the New Zealand Government has embarked upon a programme of "closing the gaps”. Hence, it may be useful to test for ethnic differences in the wage effects of training, and if such differences are found, to analyse whether they reflect rationing or comparative advantage.

The next section describes the features of the survey that is used, while Section III discusses the model specification and econometric methods. Wage equations with and without corrections for endogenous selection are reported in Section IV, while Section V concludes.

\section{THE EDUCATION AND TRAINING SURVEY}

The Education and Training Survey (ETS) was a one-off survey conducted by Statistics New Zealand as a supplement to the September 1996 Household Labour Force Survey (HLFS). It is the first major survey of job-related training in New Zealand. The survey asked respondents aged 15-64 about their participation in training provided either by 
an employer or externally (denoted in-house and external) ${ }^{5}$, and in study towards a qualification during the previous year. Although international comparisons show New Zealand to have a high participation rate in job-related training OECD (1999), the disaggregated data from the ETS reveal considerable disparities between ethnic groups. For example, the incidence of external and in-house training for people of Pacific Islands origin is approximately half that of whites, with significant gaps also for people of Maori origin and other minority groups (Table 1).

Table 1: Participation rates ino In-house and external training

\begin{tabular}{|lcccc|}
\hline & White & Maori & Pacific Island & Other minority \\
\cline { 2 - 5 } In-house training & $24.4 \%$ & $17.8 \%$ & $13.7 \%$ & $21.4 \%$ \\
External training & $14.5 \%$ & $10.1 \%$ & $4.4 \%$ & $9.7 \%$ \\
\hline Source: Gobbi (1998). & & & \\
\hline
\end{tabular}

The distinction between in-house and external training made by the survey may be a useful feature in terms of the debate about the rationing of training. ${ }^{6}$ For in-house training to go ahead, it must be beneficial for both the worker and the firm Oosterbeek (1998), whereas external training may just reflect the demands of the worker. Hence, differences in the incidence of the two types of training may support inferences about the supply curve for employer-provided training. The potential supply-side rationing of in-house training is also consistent with the finding that employer-provided training has higher returns than off-the-job training from other sources Blundell et al (1999).

A drawback of the survey is that no distinction is made between completed and ongoing training. Current in-house training may have a negative wage effect if workers pay for general training (and their share of specific training - see Hashimoto (1981) in the form of lower wages Blakemore and Low (1983). However, a growing body of evidence questions whether workers do in fact pay for general training provided by employers Acemoglu and Pischke (1999), so this drawback of the data may not be too severe. Moreover, most in-house

\footnotetext{
${ }^{5}$ The definitions used by the ETS are that in-house training is that organized by an employer primarily to meet the needs of its own employees, is conducted in-house or externally, and is delivered by the company's own employees or external training providers. External training covers all other employment-related training for the employed and unemployed.

${ }^{6}$ A further advantage of the ETS, for the purposes of measuring the wage effects of training, is that it is based on the general population, whereas many other studies are based just on youth cohorts (Lynch, 1992; Booth, 1993; Veum, 1995).
} 
training appears to be of short duration, ${ }^{7}$ so there may not be significant costs for firms to recoup in the form of lower wages. The survey also does not distinguish between training received at the current and previous employers, so the issue of portability of training across jobs is not able to be investigated. There is conflicting evidence about whether on-the-job training is portable from employer to employer Lynch (1992); Blundell et al.(1999) and the degree of portability may also vary across ethnic groups Sexton and Olsen (1994).

\section{$3 \quad$ METHODS}

\subsection{Specification and Estimation Method}

The specification is based on the following log wage equation:

$$
\ln w_{j}^{m}=\mathbf{x}_{j}^{m} \beta+\theta d_{j}^{m}+u_{j}^{m}
$$

where $\mathbf{x}_{j}^{m}$ is a vector of personal and job characteristics that affect wages of the $j$ th worker in ethnic group $m(m=1,2)$, and $d_{j}^{m}$ is some measure of training. Our interest is in testing the hypothesis $\theta^{\text {white }}=\theta^{\text {non-white }}$ for each measure of in-house and external training considered. Both the incidence of training and the number of training episodes in the previous 12 months are considered. Veum (1995) notes that training effects may be more apparent with incidence data, which will have less measurement error if it is easier for respondents to remember whether they received training rather than how many times or how many days they were trained.

However, there may be a problem in testing the hypothesis that $\theta^{\text {white }}=\theta^{\text {non-white }}$ because equation (1) may give inconsistent parameter estimates if selection of workers into training is non-random. Specifically, if training is allocated according to the selection equation (dropping superscripts):

$$
\text { Prob }\left(d_{j}=1\right)=\operatorname{prob}\left(\mathbf{z}_{j} \gamma+e_{j}>0\right)
$$

where $\mathbf{z}_{j}$ is a vector of explanatory variables determining training receipt, and

\footnotetext{
${ }^{7}$ According to Statistics New Zealand (1997), for almost 90 percent of the workers receiving in-house training, the longest training episode lasted less than one week. Veum (1995) also finds that many company training programs are quite short in duration.
} 


$$
\begin{gathered}
u_{j} \sim N(0, \sigma) \\
e_{j} \sim N(0,1) \\
\operatorname{corr}\left(u_{j}, e_{j}\right)=\rho
\end{gathered}
$$

then $d_{j}$ will be correlated with $u_{j}$, resulting in inconsistent estimates. For example, if workers participating in training are more ambitious, and if that (unobservable) ambition also gets rewarded with higher wages, then the correlation between the errors in the participation and wage equations forces a correlation between the training variable and the wage equation errors Booth (1993).

One common solution to this problem of parameter inconsistency is to add the Mills ratio from a probit model of training receipt,

$$
m{ }_{j}=\frac{\phi\left(\mathbf{z}_{j} \hat{\gamma}\right)}{\Phi\left(\mathbf{z}_{j} \hat{\gamma}\right)}
$$

to the wage equation Lynch (1992). In this framework, the $\hat{\beta}$ should be unbiased estimates once $m_{j}$ is included in the wage equation, and the statistical significance of the coefficient on this added variable, $\lambda=\rho \sigma$, provides a test of endogenous selection bias. However, the main practical problem with this procedure is that the same set of explanatory variables are likely to affect both the training receipt and the earnings equations, so one is forced to either make arbitrary exclusion restrictions, or else use the differences in functional form to secure the identification of the selectivity-corrected training impact Lynch (1992); Booth (1993). It is perhaps unsurprising, therefore, that many studies of training find statistically insignificant estimates of $\lambda$ and little impact of adding the Mills ratios to the earnings equations.

\subsection{Dependent Variable}

One factor complicating estimation of the earnings functions is that the ETS data on earnings are not continuous. Instead, they fall into five unequal intervals $(<\$ 14,000$; $\$ 14,001-\$ 22,000 ; \$ 22,001-\$ 29,000 ; \$ 29,001-\$ 39,000$ and $>\$ 39,000) .{ }^{8}$ Despite being widely used, OLS estimation of an equation with interval data as the dependent variable (implemented, for example, by using the mid-points of the intervals) is generally inconsistent

\footnotetext{
${ }^{8}$ The questionnaire allowed respondents to answer in weekly, fortnightly, monthly or annual terms but all data were converted to annual equivalents during the processing of the survey.
} 
Steward (1983). Instead, a consistent maximum likelihood procedure, which is a generalisation of the Tobit model, is used here StataCorp (1997). This model requires the end-points of the intervals to be specified (with the exception of the lower end-point for the bottom interval and the upper end-point for the top interval, which are censored). The interval regression model assumes that the distribution of the error term is normal (which is consistent with the two-step approach of adding the Mills ratio) and the estimation method also takes account of the sampling weights and uses heteroscedastically-robust variance-covariance estimators.

\subsection{Explanatory Variables}

The vector $\mathbf{x}_{j}^{m}$ includes a fairly standard set of worker characteristics that have been used as control variables in previous studies of the wage effects of training. However, the set of variables is less extensive than many studies because of the cross-sectional nature of the survey and its focus on the individual rather than on their workplace. Thus, in addition to variables measuring the amount of time that the worker spent accumulating schooling, general labour market experience and tenure at the current employer, the survey also provides variables describing the gender, marital status, occupation and industry of the worker.

Amongst these control variables, three deserve comment. The tenure variable may reflect informal training not included in the training measures, in addition to any effect it has in capturing the wage effects of job seniority. The use of control variables for occupation allows training effects to be interpreted as the wage-change within occupations; this seems appropriate because the short period over which training is recorded (that is, the previous 12 months) may preclude workers from gaining enough training to change occupations. Including controls for occupation is also consistent with previous studies Blakemore and Low (1980); Booth (1991); Veum (1995), many of which also include industry dummies, although as Lynch (1992) points out, adding industry and occupation effects appears to have only a slight effect on the coefficients for training variables. The third feature of the control variables is that gender is just treated as an intercept effect. Previous analyses with the ETS data show no significant differences in the incidence of training between men and women within ethnic groups, and no difference across men and women in the returns to education Gibson (2000). Moreover, the gender composition is constant across ethnic groups so any 
differential effects of training on men's and women's wages should not affect the comparison of interest, which is across ethnic groups.

Although the ETS has a sample of 22,257, a total of 10,443 respondents were either not employed or else had missing information on earnings and so were excluded from the analysis. ${ }^{9}$ Part-time workers ( $\left.n=2969\right)$ are excluded from the analysis because it is difficult to know from the annual earnings variable whether these workers have low wages or low labour supply. ${ }^{10}$ Also excluded were 616 workers with missing information on either training, tenure or years of schooling, leaving a final estimating sample of 8229. Although whites dominate ( $n=6746)$, almost one-fifth of the sample come from minority groups, particularly indigenous Maori ( $n=782$ ) and workers of Pacific Islands origin ( $n=397)$, while all other ethnic minorities comprise just under four percent of the sample $(n=304)$. Because all three of these minority groups have a low incidence of training, they are combined into one group for the wage equations to overcome any problems of small sample size.

Descriptive statistics for this sample are reported in Table 2 and these show that the lower level of training for the non-white workers has been preserved by the sample selection rules. The average incidence and number of episodes of in-house training for non-white workers is only three-quarters as high as for whites, while for external training the proportionate gap is slightly larger. The lower schooling, labour market experience and tenure of non-white workers is also apparent. The distributional data on the earnings intervals also shows the poorer labour market position of non-whites, with only one-sixth having earnings in the top bracket $(>\$ 39,001)$ compared with almost one-third of white workers being in this earnings bracket.

\footnotetext{
${ }^{9}$ These exclusions are unlikely to cause any sample selectivity bias because an earnings function fitted to these data gives results that are very similar to previously published results from the 1996 Census of Population (Gibson, 2000).

${ }^{10}$ Booth (1991) also excludes part-time workers when using bracketed annual earnings data to estimate the effect of training on wages.
} 
Table 2: Descriptive statistics for the sample

\begin{tabular}{|c|c|c|c|c|}
\hline & \multicolumn{2}{|c|}{ White } & \multicolumn{2}{|c|}{ Non-White } \\
\hline & Mean & Std. Dev & Mean & Std. Dev \\
\hline \multirow[t]{2}{*}{ Male } & 0.601 & $(0.490)$ & 0.608 & $(0.488)$ \\
\hline & 0.657 & $(0.475)$ & 0.671 & $(0.470)$ \\
\hline \multicolumn{5}{|l|}{ Married } \\
\hline & 18.966 & (12.013) & 16.931 & (10.499) \\
\hline \multicolumn{5}{|l|}{ Years of experience } \\
\hline Tenure (months) & 62.985 & (50.106) & 52.959 & (46.758) \\
\hline Post-primary school years & 6.081 & $(2.823)$ & 5.255 & $(2.976)$ \\
\hline \multicolumn{5}{|c|}{ In-house training } \\
\hline Received training last year? & 0.312 & $(0.463)$ & 0.231 & $(0.422)$ \\
\hline Number of training episodes & 0.678 & $(1.238)$ & 0.514 & $(1.128)$ \\
\hline \multicolumn{5}{|l|}{ External training } \\
\hline Received training last year? & 0.167 & $(0.373)$ & 0.095 & $(0.293)$ \\
\hline Number of training episodes & 0.304 & $(0.822)$ & 0.203 & $(0.765)$ \\
\hline \multicolumn{5}{|c|}{ Annual (pre-tax) earnings interval } \\
\hline Under $\$ 14,000$ & 0.044 & & 0.061 & \\
\hline$\$ 14,001$ to $\$ 22,000$ & 0.161 & & 0.287 & \\
\hline$\$ 22,001$ to $\$ 29,000$ & 0.229 & & 0.279 & \\
\hline$\$ 29,001$ to $\$ 39,000$ & 0.263 & & 0.210 & \\
\hline$\$ 39,001$ and over & 0.303 & & 0.164 & \\
\hline Sample Size & 67 & & & \\
\hline
\end{tabular}

\section{$4 \quad$ RESULTS}

The maximum likelihood results of the log earnings equations, without corrections for endogenous selection into training, are presented in Table 3. The first columns, presenting results when training is measured by incidence, suggest that white workers who received inhouse training in the previous year, have wage gains of almost nine percent, while for nonwhite workers the wage gains are 16 percent. These wage gains for white workers are within the range found in other studies e.g. Blundell et al. (1999) suggest an approximate wage effect of five percent). The wage effects for non-white workers are somewhat higher than the estimates of many studies, although similar in magnitude to the results of Flanagan (1974). The wage effects of external training are rather lower for both groups and are not statistically significant for non-whites. Hypothesis test results at the bottom of Table 3 show that the 
difference in wage effects across ethnic groups is statistically significant for in-house training $(p<0.02)$, but not for external training $(p<0.57)$.

Table 3: Effect of In-house and external training on log annual earnings by ethnic group $^{a}$

\begin{tabular}{|c|c|c|c|c|c|c|c|c|}
\hline & \multicolumn{4}{|c|}{ Training Measured by Incidence } & \multicolumn{4}{|c|}{$\begin{array}{c}\text { Training Measured by Number of } \\
\text { Episodes } \\
\end{array}$} \\
\hline & \multicolumn{2}{|c|}{ White } & \multicolumn{2}{|c|}{ Non-white } & \multicolumn{2}{|c|}{ White } & \multicolumn{2}{|c|}{ Non-white } \\
\hline & $\beta$ & $|t|$ & $\beta$ & $|t|$ & $\beta$ & $|t|$ & $\beta$ & $|t|$ \\
\hline Male (=1) & \multicolumn{2}{|c|}{$0.235(19.7)$} & \multicolumn{2}{|c|}{$0.225(10.3)$} & \multicolumn{2}{|c|}{$0.236(19.8)$} & \multicolumn{2}{|c|}{$0.225(10.2)$} \\
\hline Married (=1) & \multicolumn{2}{|c|}{$0.072(5.97)$} & \multicolumn{2}{|c|}{$0.041(1.64)$} & \multicolumn{2}{|c|}{$0.073(6.11)$} & \multicolumn{2}{|c|}{$0.048(1.94)$} \\
\hline Years of experience $^{\mathrm{b}}$ & \multicolumn{2}{|c|}{$0.023(13.2)$} & \multicolumn{2}{|c|}{$0.014(3.72)$} & \multicolumn{2}{|c|}{$0.023(13.4)$} & \multicolumn{2}{|c|}{$0.014(3.80)$} \\
\hline$(\text { Years of experience })^{2}$ & \multicolumn{2}{|c|}{$-0.047(12.5)$} & \multicolumn{2}{|c|}{$-0.026(3.27)$} & \multicolumn{2}{|c|}{$-0.047(12.8)$} & \multicolumn{2}{|c|}{$-0.027(3.37)$} \\
\hline Tenure (months) & \multicolumn{2}{|c|}{$0.002(14.2)$} & \multicolumn{2}{|c|}{$0.002(6.99)$} & \multicolumn{2}{|c|}{$0.002(14.2)$} & \multicolumn{2}{|c|}{$0.002(6.89)$} \\
\hline School years $^{c}$ & \multicolumn{2}{|c|}{$0.043(16.8)$} & \multicolumn{2}{|c|}{$0.030(6.15)$} & \multicolumn{2}{|c|}{$0.043(16.9)$} & \multicolumn{2}{|c|}{$0.030(6.10)$} \\
\hline In-house training & \multicolumn{2}{|c|}{$0.082(7.03)$} & \multicolumn{2}{|c|}{$0.151(5.82)$} & \multicolumn{2}{|c|}{$0.029(6.71)$} & \multicolumn{2}{|c|}{$0.051(5.10)$} \\
\hline External training & \multicolumn{2}{|c|}{$0.069(4.51)$} & 0.04 & $(0.95)$ & 0.032 & $(4.00)$ & 0.0 & 1.68) \\
\hline Intercept & 9.770 & $(331)$ & 9.78 & (136) & 9.772 & $(331)$ & 9.7 & 141) \\
\hline$\sigma$ & 0.325 & $(63.5)$ & 0.31 & $(33.6)$ & 0.326 & $(63.4)$ & 0.3 & 33.3) \\
\hline Wald test (slopes $=0$ ) & $\chi_{(16)}^{2}=$ & $=2969.9$ & $\chi_{(16)}^{2}$ & 546.1 & $\chi_{(16)}^{2}=$ & 2931.8 & $\chi_{(1}^{2}$ & 530.3 \\
\hline$\underset{\text { non-white: }}{\mathrm{H}_{0:}} \theta^{\text {white }}=\theta$ & & $t=2.4$ & $0.02)$ & & & $t=2.0$ & $<0.05$ & \\
\hline In-house training & & & & & & & & \\
\hline External training & & $t=0.5$ & $0.57)$ & & & $t=0.1$ & $<0.87$ & \\
\hline $\begin{array}{l}\text { Note: Estimates weighted by } \\
\text { standard errors. The sample } \\
\text { equation also contains eight o } \\
\text { a Earnings are pre-tax and are } \\
{ }^{b} \text { This is potential labour mark } \\
{ }^{\circ} \text { Equivalent full-time years of }\end{array}$ & $\begin{array}{l}\text { eported i } \\
\text { texperie } \\
\text { secondar }\end{array}$ & $\begin{array}{l}\text { in dumm } \\
\text { in interva } \\
\text { ence calc } \\
\text { y school }\end{array}$ & iables. & $\begin{array}{l}\text { ad } t \text {-stat } \\
\text { ample a } \\
\text { minus } \mathrm{p}\end{array}$ & imary s & $\begin{array}{l}\text { in hetero } \\
\text { n the no } \\
\text { chool ye }\end{array}$ & lastica & \\
\hline
\end{tabular}

These higher wage benefits of in-house training for non-whites contrast with the rather lower returns earned from other human capital characteristics; the coefficients on years of schooling and the experience quadratic for non-whites are significantly lower than for whites (at the $p<0.04$ level). Thus, while wages for full-time white workers peak after 24 years of potential labour market experience at 32 percent higher than for a worker without experience, non-whites gain only a 20 percent wage premium at peak experience. Similarly, the (Mincerian) return to post-primary schooling for non-whites is only three-quarters of that for whites, at three percent per completed year. However, the wage premia for being male (26 percent), for being married (seven percent) and for tenure (approximately two percent per year with the firm) do not vary with ethnicity. 
When training is measured by the number of episodes, the results in the last columns of Table 3 are largely the same. The wage gains from in-house training for nonwhites are still almost twice as high as for whites $(p<0.05)$ while there is no difference across ethnic groups in the effects of external training. In contrast to Veum's (1995) point about measurement error, no attenuation of the measured training effect is evident when moving away from the incidence measures, with the effect of external training for non-whites in fact becoming statistically significant at the $p<0.10$ level. Results not reported in Table 3 also show that the larger wage gains for non-whites from in-house training are not affected by the inclusion or exclusion of industry effects; if these effects are added to the model, the test of the hypothesis that $\theta^{\text {white }}=\theta^{\text {non-white }}$ yields a $t$-statistic of $2.11(p<0.04)$ when training is measured by the number of episodes.

The results for the earnings equations change only slightly once they are corrected for the potentially endogenous selection of workers who receive training (Table 4). Adding the Mills ratios from separately estimated probit equations for the receipt of in-house and external training changes several of the coefficients in the model, but does not have much effect on the coefficients on the training variables. ${ }^{11}$ Consequently, the estimated wage gains from in-house training for non-whites are still almost twice as high as for whites $(p<0.02)$ while there appears to be no difference across ethnic groups in the wage effects of external training.

\footnotetext{
${ }^{11}$ This procedure ignores any correlation in the errors of the probit equations for in-house and external training, which should not be too serious because a bivariate probit gave correlations of only -0.12 for whites and -0.04 for non-whites (standard errors of 0.08 and 0.03). Lynch (1992) also ignored correlations in probit errors of 0.12 and estimated separate equations. An alternative approach used by Veum (1995) is to generate the selectivity terms from a multinomial logit, where the choices are no training, in-house training or external training. But this approach requires mutually exclusive categories and in the current sample 11 percent of those receiving training received it in both in-house and external forms.
} 
Table 4: Selectivity-corrected estimates of log annual earnings functions

\begin{tabular}{|c|c|c|c|c|c|}
\hline & \multicolumn{3}{|c|}{ Training Measured by Incidence } & \multicolumn{2}{|c|}{$\begin{array}{c}\text { Training Measured by Number of } \\
\text { Episodes }\end{array}$} \\
\hline & \multicolumn{2}{|c|}{ White } & Non-white & White & Non-white \\
\hline & $\beta$ & $|t|$ & $|t|$ & $|t|$ & $|t|$ \\
\hline Male (=1) & 0.17 & $(5.83)$ & $0.206(1.39)$ & $0.176(5.89)$ & $0.196(1.32)$ \\
\hline Married (=1) & 0.17 & $(3.09)$ & $0.136(0.43)$ & $0.171(3.02)$ & $0.197(0.63)$ \\
\hline Years of experience ${ }^{b}$ & 0.04 & $(3.16)$ & $0.010(0.92)$ & $0.045(3.08)$ & $0.008(0.74)$ \\
\hline$(\text { Years of experience })^{2}$ & -0.10 & $(2.83)$ & $-0.020(0.48)$ & $-0.106(2.75)$ & $-0.017(0.40)$ \\
\hline Tenure (months) & -0.00 & $(2.18)$ & $0.003(0.93)$ & $-0.003(2.09)$ & $0.003(1.08)$ \\
\hline School years ${ }^{c}$ & 0.16 & $(3.76)$ & $0.026(0.40)$ & $0.164(3.63)$ & $0.024(0.37)$ \\
\hline In-house training & 0.08 & $(7.13)$ & $0.150(5.81)$ & $0.029(6.79)$ & $0.051(5.06)$ \\
\hline External training & 0.06 & $(4.43)$ & $0.042(0.94)$ & $0.031(3.86)$ & $0.029(1.66)$ \\
\hline$\lambda_{1}$ (in-house probit) & 1.33 & (2.93) & $-0.279(0.33)$ & $1.316(2.88)$ & $-0.444(0.52)$ \\
\hline$\lambda_{2}$ (external probit) & -3.13 & (3.37) & $0.197(0.12)$ & $-3.057(3.24)$ & $0.301(0.19)$ \\
\hline Intercept & 6.35 & $(4.52)$ & $9.734(3.55)$ & $6.475(4.54)$ & $9.680(3.52)$ \\
\hline$\sigma$ & 0.32 & $(63.1)$ & 0.317 (33.6) & $0.325(63.0)$ & 0.317 (33.3) \\
\hline Wald test (slopes $=0$ ) & $\chi_{(18)}^{2}$ & 2994.2 & $\chi_{(18)}^{2}=555.6$ & $\chi_{(18)}^{2}=2960.9$ & $\chi_{(18)}^{2}=538.4$ \\
\hline$\underset{\text { non-white }}{\mathrm{H}_{0:}} \theta$ whit & \multicolumn{3}{|c|}{$t=2.42(p<0.02)$} & \multicolumn{2}{|c|}{$t=1.99(p<0.05)$} \\
\hline \multicolumn{6}{|l|}{ In-house training } \\
\hline External training & \multicolumn{3}{|c|}{$t=0.55(p<0.59)$} & \multicolumn{2}{|c|}{$t=0.12(p<0.91)$} \\
\hline
\end{tabular}

It is difficult to assess the impact of endogenous selection into training programmes because there is no clear pattern amongst the coefficients on the Mills ratios. The errors in the wage equation for white workers appear to be positively correlated with the unobservables in the participation equation for in-house training, but negatively correlated with the unobservables from the probit for external training, while no significant relationships appear amongst the unobservables for non-white workers. ${ }^{12}$ This uncertainty may just reflect the commonality of the explanatory variables used in the wage and training participation probit equations, with the identification resting on functional form assumptions. ${ }^{13}$ These probit

\footnotetext{
${ }^{12}$ This is not directly observed in Table 4 but can be inferred from the coefficients on the Mills' ratio, given that $\lambda=\rho \sigma$ and $\sigma>0$.

${ }^{13}$ However, the results of testing the hypothesis that $\theta^{\text {white }}=\theta^{\text {non-white }}$ are very similar if the exclusion restrictions amongst the industry and occupation dummies are changed and if the selection terms are generated from a multinomial logit model (where workers receiving both types of training were allocated to the type with more episodes).
} 
equations, which are reported in Appendix Table 1, show that formal schooling and general labour market experience raise the probability of receiving both types of training for white workers. In contrast, experience has no effect on either type of training for non-white workers and schooling only affects participation in external training.

\section{SUMMARY AND INTERPRETATION}

This paper has examined the effects of job-related training, provided either by an employer or externally, on the wages of white and non-white workers in New Zealand. In the sample drawn from the Education and Training survey, the average incidence and number of episodes of in-house training for non-white workers is only three-quarters as high as for whites, while for external training it is only two-thirds as high. The results from the estimated earnings functions suggest that the wage benefits from in-house training are almost twice as high for non-white workers as for whites, while there is no difference across ethnic groups in the wage effects of external training. These patterns are the same whether training is measured by incidence or by the number of episodes, whether industry effects are included or excluded, and whether corrections for the potentially endogenous selection of workers into training programmes are attempted.

Therefore, smaller expected wage benefits are unlikely to cause a poorer response to training opportunities, which was one reason suggested by Shields and Wheatley Price (1999) for the lower incidence of job-related training for ethnic minorities. It is less clear from these results whether employers' beliefs about low returns from training non-white employees contribute to their lower incidence of training. The high wage benefits observed from in-house training for non-whites may reflect some justifiable rationing of the supply of this training by employers if it is more costly to train these workers. One contributor to this higher cost may be labour turnover. Transition data from the HLFS suggest that non-white workers in 1996 were twice as likely as white workers to not be employed in the following quarter, with an average of ten percent moving into either unemployment or non-participation. Hence, employers may respond to this higher turnover rate by directing non-white workers into only those training programmes that bring the most immediate and highest payoffs. But this lack of training may then contribute to future labour turnover, if firms respond to falls in demand by releasing workers whose training they have not invested in.

If the rationing of in-house training for non-white workers is not justified by cost considerations, the view of OECD (1999) that there may not be an efficiency cost of 
extending the provision of training to groups with low incidence may be correct. Qualitative questions in the ETS about factors making it hard for respondents to complete in-house training may be relevant to this view of inefficient rationing. Results from these questions show that "lack of employer support” was listed by a significantly higher proportion of nonwhite workers than white workers. It is apparent therefore, that although the results in this paper confirm significant ethnic differences in the wage effects of some forms of job-related training, more information is needed to determine if those differences indicate the need for public intervention designed to alter the access to training for minority group workers.

\section{REFERENCES}

Acemoglu, D., and Pischke, J-S. (1999) "Beyond Becker: Training in Imperfect Labour Markets” Economic Journal 109(Feb): F112-F142.

Altonji, J. and Spletzer, J. (1991) "Worker Characteristics, Job Characteristics, and the Receipt of on-the-job training”, Industrial and Labor Relations Review, 45(1): 58-79.

Arulampalam, S., and Booth, A. (1997) "Who Gets Over the Training Hurdle? A Study of the Training Experience of Young Men and Women in Britain”, Journal of Population Economics 10(1): 156-182.

Blakemore, A., and Low, S. (1983) "Race and the Acquisition of and Returns to on-the-job training” Industrial Relations 22(3): 374-386.

Blundell, R., Dearden, L., Meghir, C. and Sianesi, B. (1999) "Human Capital Investment: The Returns from Education and Training to the Individual, the Firm and the Economy”, Fiscal Studies, 20. 1-23.

Booth, A. (1991) "Job-Related Formal Training: Who Receives it and What is it Worth?" Oxford Bulletin of Economics and Statistics 53(3): 281-294.

Booth, A. (1993) "Private Sector Training and Graduate Earnings" Review of Economics and Statistics 75(1): 164-170.

Duncan, G., and Hoffman, S. (1979) "On-the-Job Training and Earnings Differences by Race and Sex” Review of Economics and Statistics 61(4): 594-603.

Flanagan, R. (1974) “Labor Force Experience, Job Turnover, and Racial Wage Differentials” Review of Economics and Statistics 56(4): 521-529.

Gibson, J. (2000) "Sheepskin Effects in the Returns to Education in New Zealand: Do they Differ by Ethnic Groups?” New Zealand Economic Papers 34(2): 210-226.

Gobbi, M. (1998), "Participation in Post-Compulsory Education and Training in New Zealand” Labour Market Bulletin 2(1-2): 108-126

Groot, W., Hartog, J., and Oosterbeek, H. (1994) "Costs and Revenues of Investments in Enterprise-Related Schooling” Oxford Economic Papers 46(4): 658-677.

Greenhalgh, C., and Stewart, G. (1987) “The Effects and Determinants of Training” Oxford Bulletin of Economics and Statistics 49(2): 171-190. 
Hashimoto, M. (1981) “Firm-Specific Human Capital as a Shared Investment” American Economic Review 71(3): 475-482.

Lynch, L. (1992) "Private Sector Training and the Earnings of Young Workers” American Economic Review 82(1): 299-312.

Oosterbeek, H. (1998) “Unravelling Supply and Demand Factors in Work-Related Training” Oxford Economic Papers 50(2): 266-283.

Organisation of Economic Cooperation and Development [OECD], (1999) "Training of Adult Workers” OECD Employment Outlook June 1999 OECD, Paris.

Sexton, E., and Olsen, R. (1994), “The Returns to On-The-Job Training: are they the same for Blacks and Whites?” Southern Economic Journal 61(2): 328-342.

Shields, M., and Wheatley-Price, S. (1999) "Ethnic Differences in the Incidence and Determinants of Employer-Funded Training in Britain” Scottish Journal of Political Economy 46(5): 523-551.

StataCorp (1997), Stata Statistical Software: Release 5.0, College Station: Stata Corporation.

Statistics New Zealand (1997) Hot Off the Press: Education and Training Survey September 1996 Quarter, Statistics New Zealand: Wellington.

Steward, M. (1983) "On Least Squares Estimation When the Dependent Variable is Grouped”, Review of Economic Studies 50(4): 737-753.

Te Puni Kokiri (1998) "Progress Towards Closing Social and Economic Gaps Between Maori and Non-Maori” Ministry of Maori Development, Wellington.

VandenHeuvel, A. and Wooden, M. (1997) Participation of Non-English-SpeakingBackground Immigrants in Work-Related Training, Ethnic and Racial Studies, 20(4): 830-848.

Veum, J. (1995) “Sources of Training and Their Impact on Wages” Industrial and Labor Relations Review 48(4): 812-826.

Veum, J. (1996) “Gender and Race Differences in Company Training” Industrial Relations 35(1): 32-44. 
Appendix Table : Probit Estimates of the Determinants of Training Type by Ethnic Group $^{a}$

\begin{tabular}{|c|c|c|c|c|}
\hline & \multicolumn{2}{|c|}{ In-house Training } & \multicolumn{2}{|c|}{ External Training } \\
\hline & White & Non-white & White & Non-white \\
\hline & $\partial P / \partial X \quad|t|$ & $\partial P / \partial X \quad|t|$ & $\partial P / \partial X \quad|t|$ & $\partial P / \partial X \quad|t|$ \\
\hline Male (=1) & $-1.55(1.02)$ & $-0.17(0.06)$ & $-1.00(0.84)$ & $1.48(0.87)$ \\
\hline Married (=1) & $3.98(2.55)$ & $8.27(2.88)$ & 1.98 (1.62) & $-2.61(1.40)$ \\
\hline Years of experience ${ }^{b}$ & $1.11(4.93)$ & $-0.38(0.79)$ & $0.50(2.79)$ & $0.05(0.17)$ \\
\hline$(\text { Years of experience })^{2}$ & $-2.95(5.98)$ & $0.17(0.15)$ & $-1.33(3.30)$ & $-0.39(0.59)$ \\
\hline Tenure (months) & $0.10(6.64)$ & $0.12(4.03)$ & $-0.02(1.45)$ & $0.01(0.37)$ \\
\hline School years $^{c}$ & $1.53(5.36)$ & $0.51(0.98)$ & $1.57(7.16)$ & $0.66(2.27)$ \\
\hline Predicted probability & 0.298 & 0.209 & 0.151 & 0.074 \\
\hline Psuedo- $R^{2}$ & 0.071 & 0.091 & 0.064 & 0.086 \\
\hline Wald test (slopes $=0$ ) & $\chi_{(14)}^{2}=419.5$ & $\chi_{(14)}^{2}=102.5$ & $\chi_{(14)}^{2}=262.1$ & $\chi_{(14)}^{2}=63.8$ \\
\hline \multicolumn{5}{|c|}{$\begin{array}{l}\text { Note: Estimates weighted by population sampling weights and } t \text {-statistics based on heteroscedastically- } \\
\text { consistent standard errors. The sample size is } N=6746 \text { in the White sample and } N=1483 \text { in the non-white } \\
\text { sample. Each equation also contains eight occupational dummy variables and an intercept. } \\
{ }^{\text {a }} \text { The reported probit coefficients give the change in the probability (x100) of participating in training for a unit } \\
\text { change in each explanatory variable. } \\
{ }^{b} \text { This is potential labour market experience calculated as age minus post-primary school years minus } 12 \text {. } \\
{ }^{c} \text { Equivalent full-time years of secondary school and post-secondary school educational study. }\end{array}$} \\
\hline
\end{tabular}

